\title{
Ortaöğretim Öğrencilerinin Spora Yönelik Tutumlarının Bazı Değişkenlere Göre İncelenmesi (Kırşehir İli Örneği)
}

\author{
Turan BAŞKONUŞ \\ Milli Ĕgitim Bakanlı̆̆ 1 \\ baskonusturan@gmail.com \\ ORCID ID: https://orcid.org/0000-0001-8932-7656
}

\begin{tabular}{lrr} 
Araştırma Makalesi & DOI: $10.31592 /$ aeusbed.730674 \\
\hline Geliş Tarihi: 01.05 .2020 & Revize Tarihi: 20.06 .2020 & Kabul Tarihi: 23.06 .2020
\end{tabular}

\section{Atıf Bilgisi}

Başkonuş, T. (2020). Ortaöğretim öğrencilerinin spora yönelik tutumlarının bazı değişkenlere göre incelenmesi (Kırşehir ili örneği). Ahi Evran Üniversitesi Sosyal Bilimler Enstitüsü Dergisi, 6(2), 365-376.

\section{ÖZ}

$\mathrm{Bu}$ araştırmanın amacı ortaöğretim öğrencilerinin spora yönelik tutumlarının betimlenmesidir. Araştırmaya 219 (125 kadın, 94 erkek) öğrenci gönüllük esasına göre katılmıştır. Bu araştırmada tarama yöntemi kullanılmıştır. Araştırmada, veri toplama sürecinde "Kişisel Bilgiler Formu" ve "Spora Yönelik Tutum Ölçeği" kullanılmıştır. Araştırma verilerinin test edilmesinde 0.05 anlam düzeyi alınmıştır. Verilerin analizinde alt probleme ilişkin maddeler gruplandırılarak, frekans (f), yüzde (\%), ağırlıklı ortalama $(\bar{X})$ ve standart sapma (SS) gibi betimsel istatistiklerle birlikte bağımsız t-testi ve ANOVA teknikleri kullanılmıştır. Anlamlı farklılığın etki büyüklüğünü hesaplamak için Cohen'd kullanılmıştır. Araştırma sonuçları, ortaöğretim öğrencilerinin spora ilişkin tutumlarının genel olarak orta düzeyde olduğunu göstermektedir. Alt boyutlarda; spora ilgi duyma boyutunda yüksek, sporla yaşama ve aktif spor yapma alt boyutlarında orta düzeydedir. Sınıf seviyesi ve cinsiyet değişkenleri öğrencilerin spora ilişkin tutumlarında anlamlı farklılık göstermemektedir. Bununla birlikte sportif etkinliklere katılım durumları öğrencilerin spora yönelik tutumlarında anlamlı farklılık göstermiştir. Ölçek genelinde ve alt boyutlarda sportif etkinliklere katılırım diyen öğrencilerin ortalamaları sportif etkinliklere katılmam diyen öğrencilerin ortalamalarından yüksektir. Ölçek genelinde görülen bu anlamlı farklılığın etki büyüklüğü orta düzeydedir. Spora ilgi duyma ve sporla yaşama boyutlarındaki etki büyüklükleri orta düzeyde, aktif spor yapma boyutunda görülen etki büyüklüğü ise geniş düzeydedir. Araştırma sonuçları ilgili literatür kapsamında tartışılmış ve bazı öneriler sunulmuştur. Anahtar Kelimeler: Spor, fiziksel aktivite, hareket ve egzersiz, tutum.

\section{An Investigation of Secondary School Students' Attitudes Toward Sports According to Some Variables (A Case of Kırşehir province)}

\begin{abstract}
The aim of this study was to describe secondary school students' attitudes toward sports. Two hundred nineteen (125 females, 94 males) students participated in the study on a voluntary basis. The screening method was used in this study. In the study, the "Personal Information Form" and "Sport-Oriented Attitude Scale" were used in the data collection process. A significance level of 0.05 was used to test the research data. In the analysis of the data, the items related to the sub-problem were grouped, and the independent t-test and ANOVA techniques were used together with descriptive statistics such as frequency (f), percentage (\%), weighted average $(\bar{X})$, and standard deviation (SD). Cohen's d was used to calculate the effect size of the significant difference. The results of the study showed that secondary school students' attitudes toward sports were generally moderate. The variables of grade level and gender did not show a significant difference in students' attitudes toward sports. Nevertheless, participation in sports activities showed a significant difference in students' attitudes toward sports. The averages of students who indicated that they would participate in sports activities were higher than the averages of students who indicated that they would not participate in sports activities in the overall scale and in the sub-dimensions. The effect size of this significant difference observed in the overall scale was moderate. The effect sizes in the dimensions of being interested in sports and living with sports were moderate, and the effect size observed in the dimension of doing sports actively was large. The results of the study were discussed within the context of the relevant literature, and some suggestions were provided.
\end{abstract}

Keywords: Sports, physical activity, movement and exercise, attitude.

\section{Giriş}

Hareket etme ihtiyacı insanın doğasında var olan önemli bir unsurdur. Gelişen teknoloji ve buna bağlı olarak toplumların değişen yaşam koşulları insanı hareketsiz bir yaşama doğru sürüklemektedir. Doğumdan yetişkinlik çağına kadar olan dönemde insanın sağlıklı büyümesi ve 
gelişmesi için en önemli unsurlardan biri hareket etmedir. Bununla birlikte sporun insan hayatındaki yeri ve önemi toplumlar tarafından önemli görülmüş ve sağlıklı bir yaşam için spor yapmanın gerekliliği üstünde önemle durulan bir konu haline gelmiştir.

Spor, insanların ferdi veya toplu olarak fiziki, ruhi ve düşünme kabiliyetini kendine ve bir rakibine karşı, önceden belirlenmiş bir düzen içinde başarı kazanmaya yönelik ve mücadele heyecanım yaşamak için yaptığı beden hareketlerinin bütünü (Çınar, 2015), bir başka tanımda ise, fiziksel ve zihinsel sağllğı korumak ve geliştirmek, sosyal ilişkiler kurmak, eğlenmek ve hoşça vakit geçirmek veya yarışmalarda mücadele ederek kazanmak amacıyla organize ya da plansız olarak yapılan fiziksel aktiviteler (Karahüseyinoğlu, 2015) olarak tanımlanmıştır. Günümüzde de özellikle gelişmiş ülkelerde sağlığı koruma amaçlı spor yapmanın ne denli etkili olduğunun keşfedilmesi, sporun bir yaşam tarzı olarak ele alınmasına neden olmuştur (Mengütay, Demir ve Coşan, 2002). Sporun önemini anlayan toplumlar bireylerin spora yönelmeleri konularında birtakım düzenlemeler yapmışlar ve bu kapsamda özellikle de eğitim alanındaki düzenlemelerde spora büyük önem vermişlerdir. Oyunu kurallarına göre oynama ve rakibe saygı (Pepe, Kara, Özkurt ve Dalaman, 2019) olarak tanımlanan sportmenlik de sporda önemli görülen kavramlardan biridir.

Günümüzde beden eğitimi ve spor, yetişmekte olan nesillere fikren ve bedenen sağlik kazandıran bir faaliyet alanı olarak kabul edilmektedir. Beden eğitimi ve spor; eğitim programlarının bütünleyici bir parçası olması nedeniyle öğrencilerin fiziksel aktiviteler aracılığıyla psikomotor, bilişsel, duyuşsal ve sosyal alanda gelişimine, sosyal yaşantısının içinde sporu hayat tarzı hâline getirmesine, okul dışı serbest zamanlarını kültürel ve sportif etkinliklerle değerlendirmesine katkıda bulunur (Millî Eğitim Bakanlığı [MEB], 2018)

Spor, insanların fiziksel, zihinsel ve sosyal refahına katkıda bulunur (Armstrong, Welsman ve Kirby, 1998). Spora yönelen bireylerin amac1, eğlenmek, dinlenmek ve hoşça vakit geçirmekten öteye geçmiş durumdadır. Günümüzde spor sağlıklı olmak, güç kazanmak, sosyal bir çevre edinmek ya da para kazanmak gibi pek çok amaca yönelebilmektedir (Karahüseyinoğlu, 2015). Spor, sağlıklı nesillerin eğitiminde ve dolayısıyla çağdaş toplumların yaratılmasında eğitimin ayrılmaz bir parçasıdır (Yetim, 2000). Egzersizler günlük aktivitelerin bir parçası haline getirilerek, en kolay ve eğlenceli olanları seçilerek, isteyerek yapılmalıdır (Akın, 2017).

İnceoğlu'na (2011, s. 16) göre tutum, kişinin dış dünyasındaki bir obje veya duruma yönelik olarak kendisinde var olan tepki eğilimidir. Farklı bir ifadeyle kişinin bir olay veya nesne karşısında göstermesi beklenen davranışlardır. Turgut ise (1995, s. 155) tutumu, kişinin herhangi bir durum, obje ya da kişilere, olumlu veya olumsuz yönde davranış göstermesi olarak tanımlamıştır. Başka bir tanımda ise tutum, psikolojik bir öğeye karşı tercih hakkının kullanılıp kullanılmamasıyla ilgili öğrenilen eğilim şeklinde tanımlanmıştır (Tekindal, 2009, s. 178). Hogg ve Vaughan'a (2006) göre tutum, doğrudan gözlemlenebilir olmasa da davranışlarımızı yönlendiren bir yapıdır. İyi spor tutum ve davranışları, gençlerin sadece ruh hallerini geliştirmelerine ve özgüvenlerini geliştirmelerine olanak vermekle kalmaz, aynı zamanda psikolojik hastalıkların semptomlarını da azaltır veya ortadan kaldırır (Jianzhong, 2004). Tutum, duygu ve düşünceleri içeren içsel bir durumdur. Bu yönüyle tutumlar bireylerin davranışlarını anlamada yol gösterici yönüyle önemlidir.

Gelişim çağında olan ortaöğretim öğrencilerinin sağlıklı bireyler olmaları sportif etkinliklere hayatlarında ne kadar yer verdikleri ile yakından ilişkilidir. Gençleri hem kötü alışkanlıklardan uzak tutmak hem de günlük yaşamlarında sağlıklı tutabilmek için küçük yaşlardan itibaren kazandırılan spora yönelik olumlu tutum önem taşımaktadır. Bu bakımdan orta öğretim öğrencilerinin spora yönelik tutumları önemli görülerek bu araştırma ile ortaöğretim öğrencilerinin spora yönelik tutumlarının betimlenmesi amaçlanmıştır. Bu kapsamda aşağıdaki araştırma sorularına cevaplar aranmıştır:

- Ortaöğretim öğrencilerinin spora yönelik tutumları ne düzeydedir?

- Ortaöğretim öğrencilerinin spora yönelik tutumları cinsiyet değişkenine göre anlamlı olarak farklılaşmakta mıdır? 
- Ortaöğretim öğrencilerinin spora yönelik tutumları sınıf seviyesi değişkenine göre anlamlı olarak farklılaşmakta mıdır?

- Ortaöğretim öğrencilerinin spora yönelik tutumları sportif etkinliklere katılma durumu değişkenine göre anlamlı olarak farklılaşmakta mıdır?

\section{Yöntem}

Deneysel olmayan araştırmaların birçok türü olmasına karşın en bilinen örneği tarama türüdür (Tabachnick ve Fidell, 2015). Bu araştırmada da tarama modeli kullanılmıştır. Bu kapsamda bu çalışmanın ilk kısmında ortaöğretim öğrencilerinin spora ilişkin tutumlarının betimlenmesi amaçlanmıştır. Araştırmanın ikinci kısmında cinsiyet, sınıf seviyesi ve sportif etkinliklere katılma durumu değişkenlerinin öğrencilerin spora ilişkin tutumlarında anlamlı farklılık gösterip göstermedikleri incelenmiştir. Araştırma kapsamında 11.03.2020 tarih ve E-5293532 sayı ile Kırşehir Milli Eğitim Müdürlüğünden (Rehberlik Araştırma Merkezi) etik kurul ve Kırşehir Valiliğinden araştırma izni alınmıştır.

\section{Çalışma Evren ve Örneklemi}

Araştırmanın ulaş1labilen evreni, Kırşehir merkezde öğrenim gören anadolu lisesi öğrencileridir. Bu evrenden, rastgele yolla seçilen 234 öğrenci çalışma örneklemini oluşturmaktadır. Öğrencilere gönderilen ölçme araçlarından 15 tanesi hatalı kodlama, boş vb. nedenlerden dolay1 değerlendirmeye alınmamış, toplam 219 öğrenciden elde edilen veriler değerlendirmeye alınmıştır. Ölçme araçlarının doldurulmasında gönüllük esası aranmıştır. Örnekleme ait bilgiler Tablo 1'de sunulmuştur.

Tablo 1

Örnekleme Ait Bilgiler

\begin{tabular}{|c|c|c|c|c|}
\hline \multicolumn{3}{|l|}{ Bağımsız Değişkenler } & \multirow{2}{*}{$\frac{\mathrm{f}}{94}$} & \multirow{3}{*}{$\frac{\%}{42,9}$} \\
\hline & & Erkek & & \\
\hline Cinsiyet & & Kadın & 125 & \\
\hline \multirow{4}{*}{\multicolumn{2}{|c|}{ Sinıf Düzeyi }} & 9. Sinıf & 62 & 28,3 \\
\hline & & 10. Sinıf & 53 & 24,2 \\
\hline & & 11. Sinıf & 55 & 25,1 \\
\hline & & 12. Sinıf & 49 & 22,4 \\
\hline \multirow{2}{*}{\multicolumn{2}{|c|}{$\begin{array}{l}\text { Sportif etkinliklere katılma } \\
\text { durumu }\end{array}$}} & Katılırım & 121 & 55,3 \\
\hline & & Katılmam & 98 & 44,7 \\
\hline
\end{tabular}

Tablo 1'de çalışma örnekleminin \%42,9'unu ( $\mathrm{n}=94)$ erkek öğrencilerin, \%57,1'ini ( $\mathrm{n}=125)$ ise kadın öğrencilerin oluşturduğu görülmektedir. Öğrencilerin \%28,3'ü $(n=62) 9$. sinıf, \%24,2'si $(n=53)$ 10. sinıf, \%25,1'i $(n=55) 11$. sınıf, \%22,4'ü $(n=49) 12$. sinıf öğrencisidir. Öğrencilerin \%55,3'ü $(n=121)$ sportif etkinliklere katılıyor iken \%44,7'si (n=98) katılmamaktadır.

\section{Veri Toplama Araçları}

Bu süreçte kişisel bilgiler formu ve spora yönelik tutum ölçeği kullanılmıştır.

\section{Kişisel Bilgi Formu (KBF)}

Araştırmacı tarafindan hazırlanan formda, tutumlar üzerinde farklılık oluşturabileceği düşünülen bazı bağımsız değişkenler yer almaktadır. Bu değişkenler öğrenciler ile ilgili demografik bilgileri (cinsiyet, sınıf seviyesi ve sportif etkinliklere katılma durumu) genel olarak ele almış ve veriler sınıflama sorular olarak KBF'de yer almıştır. 


\section{Spora Yönelik Tutum Ölçeği}

Şentürk (2015) tarafindan geliştirilmiş olup 25 madde ve 3 boyuttan oluşmaktadır. Spora ilgi duyma boyutu (Cronbach alpha: .98) 1.,2.,3.,4.,5.,6. 7.,8.,9.,10.,11. ve 12. maddelerden, sporla yaşama boyutu (Cronbach alpha: .98) 13.,14.,15.,16.,17.,18. ve 19. maddelerden, aktif spor yapma boyutu (Cronbach alpha: .95) 20.,21.,22.,23.,24. ve 25. maddelerden oluşmaktadır. Ölçeğin geneline ilişkin Cronbach alpha .97 olarak bulunmuştur. 5'li Likert tipi bir ölçektir. Ölçekteki maddeler kesinlikle katılıyorum "5", katılıyorum "4", kararsızım " 3 ", katılmıyorum "2" ve hiç katılmıyorum " 1 " şeklinde düzenlenmiştir.

\section{Verilerin Analizi}

Elde edilen veriler analiz için SPSS 20.0 paket programına yüklenmiştir. Araştırma verilerinin test edilmesinde 0.05 anlam düzeyi alınmıştır. Elde edilen betimsel verilerin analizinde frekans (f), yüzde (\%), ağırlıklı ortalama $(\overline{\mathrm{X}})$ ve standart sapma (SS) değerleri kullanılmıştır. İlişkisel istatistik yöntemleri yapılmadan önce verilerin homojenliğine bakılmış ve normal dağılım gösterip göstermediği incelenmiştir. Verilerin normal dağılımları ile ilgili bulgulara Tablo 2'de yer verilmiştir.

Tablo 2

Normal Dağılım ile İlgili Bulgular

\begin{tabular}{lllrr}
\hline & & Çarpıklık & Basıklık \\
\hline & GENEL & İstatistik &,- 357 &,- 261 \\
& Spora İlgi Duyma & Standart hata &, 164 &, 327 \\
Spora Yönelik Tutum & İstatistik &,- 400 &,- 270 \\
Ölçeği & Boyutu & Standart hata &, 164 &, 327 \\
& Sporla Yaşama Boyutu & İstatistik &,- 282 &,- 474 \\
& Standart hata &, 164 &, 327 \\
& Aktif Spor Yapma & İstatistik &,- 179 &,- 714 \\
& Boyutu & Standart hata &, 164 &, 327 \\
\hline
\end{tabular}

Spora yönelik tutum ölçeği çarpıklık $(-, 357)$ ve basıklık $(-, 261)$ değer aralığında olması verilerin normal dağıldığını göstermektedir (Büyüköztürk, 2014; George ve Mallery, 2010).

$\mathrm{Bu}$ sonuçlar doğrultusunda araştırma verilerinin analizi sürecinde parametrik hipotez testleri kullanılmışır. Bu kapsamda öğrencilerinin spora yönelik tutumlarının ikili gözenekli değişkenlere göre incelenmesinde bağımsız t-testi, üç ve daha fazla gözenekli değişkenlere göre incelenmesinde ANOVA teknikleri uygulanmıştır. Tukey testi ile anlamlı farklılığın kaynağı belirlenmiştir. Bağımsız t-testi sonuçlarında anlamlı farklılığın etki büyüklüğünü hesaplamak için Cohen'd kullanılmıştır.

Öğrencilerin ölçekte yer alan maddeler için verdikleri cevaplar beşli likert tipinde olup değerlendirme ölçeği grup değer aralığının tespitinde; “a = Ranj / Yapılacak Grup Sayısı” formülü kullanılmıştır (Taşdemir, 2003). Buna göre değerlendirme ölçeği şöyledir:

Tablo 3

Ölçeklerin Puanlandırılması Verilen Ağırlık Nitelik Grupları

\begin{tabular}{clr}
\hline & \multicolumn{1}{c}{ Spora Yönelik Tutum Ölçeği } & \\
\hline Verilen Ağırlık & Nitelik grubu & Sınırı \\
\hline 5 & Kesinlikle Katılıyorum & $4.20-5.00$ \\
4 & Katıllyorum & $3.40-4.19$ \\
3 & Kararsızım & $2.60-3.39$ \\
2 & Katılmıyorum & $1.80-2.59$ \\
1 & Hiç Katılımıorum & $1-1.79$ \\
\hline
\end{tabular}




\section{Bulgular}

Bulgular, Öğrencilerinin Spora Yönelik Tutumları ile İlgili Bulgular ve Öğrencilerin Spora Yönelik Tutumları ile İlgili İlişkisel Bulgular olmak üzere iki alt başlıkta verilmiştir.

\section{Öğrencilerinin Spora Yönelik Tutumları ile İlgili Bulgular}

Ortaöğretim öğrencilerinin spora yönelik tutumları ile ilgili bulgular Tablo 4 'te yer almaktadır.

Tablo 4

Öğrencilerinin Spora Yönelik Tutumları

\begin{tabular}{lrrr}
\hline & $\bar{X}$ & SS & Düzey \\
\hline GENEL & 3,36 &, 961 & Kararsızım \\
Spora İlgi Duyma Boyutu & 3,41 &, 979 & Kat1liyorum \\
Sporla Yaşama Boyutu & 3,28 & 1,011 & Kararsizım \\
Aktif Spor Yapma Boyutu & 3,16 & 1,098 & Kararsızım \\
\hline
\end{tabular}

Tablo 4 incelendiğinde öğrencilerinin spora ilişkin tutumları genel olarak $(\overline{\mathrm{X}}=3,36)$ orta (kararsızım) düzeydedir. Alt boyutlar incelendiğinde; spora ilgi duyma $(\overline{\mathrm{X}}=3.41)$ yüksek (katıllyorum), Sporla Yaşama $(\overline{\mathrm{X}}=3.28)$ ve aktif spor yapma $(\overline{\mathrm{X}}=3.16)$ alt boyutlarında orta (kararsızım) düzeyde olduğu görülmektedir. Bu durum ortaöğretim öğrencilerinin spora yönelik orta düzeyde tutuma sahip olduklarını göstermektedir.

\section{Öğrencilerin Spora Yönelik Tutumları ile İlgili İlişskisel Bulgular}

Ortaöğretim öğrencilerinin spora yönelik tutumları ile ilgili ilişkisel bulgular Tablo 5 ile Tablo 8 'de yer almaktadır.

Tablo 5

Öğrencilerin Cinsiyetlerine Göre Spora Yönelik Tutumlarına İlişkin T-Testi Sonuçları

\begin{tabular}{llrrrrr} 
& Cinsiyet & $\mathrm{N}$ & $\bar{X}$ & $\mathrm{SS}$ & $\mathrm{t}$ & $\mathrm{p}$ \\
\hline \multirow{2}{*}{ GENEL } & Erkek & 94 & 3,36 & 1,073 & \multirow{2}{*}{, 714} & \multirow{2}{*}{, 476} \\
& Kadın & 125 & 3,27 &, 869 & & \\
Spora İlgi Duyma Boyutu & Erkek & 94 & 3,42 & 1,102 &, 376 &, 707 \\
\multirow{2}{*}{ Sporla Yaşama Boyutu } & Kadın & 125 & 3,37 &, 879 & & \\
\multirow{2}{*}{ Aktif Spor Yapma Boyutu } & Erkek & 94 & 3,37 & 1,113 &, 029 &, 526 \\
& Kadın & 125 & 3,28 &, 929 & & \\
& Erkek & 94 & 3,23 & 1,147 & 1,254 &, 211 \\
\hline
\end{tabular}

Tablo 5 incelendiğinde genel olarak erkek öğrencilerin ortalamalarının $(\overline{\mathrm{X}}=3,36)$ kadın öğrencilerin ortalamalarından $(\bar{X}=3,27)$ yüksek olduğu görülmektedir. Alt boyutlara bakıldığında; tüm alt boyutlarda erkek öğrencilerin ortalamalarının kadın öğrencilerin ortalamalarından yüksek olduğu görülmektedir. $\mathrm{T}$ testi sonucunda gruplar arası ortalama farkların anlamlı olmadığı ( $>$ >05) görülmektedir.

Tablo 6

Öğrencilerin Sinıf Seviyelerine Göre Spora Yönelik Tutum Ortalamaları ve Standart Sapma Değerleri

\begin{tabular}{llrrr}
\hline & Sinıf Seviyesi & N & $\bar{X}$ & SS \\
\hline \multirow{3}{*}{ GENEL } & 9. Sinif & 62 & 3,20 &, 950 \\
& 10. Sinif & 53 & 3,37 &, 972 \\
Spora İlgi Duyma Boyutu & 11. Sinif & 55 & 3,22 &, 973 \\
& 12. Sinif & 49 & 3,46 &, 952 \\
& 9. Sinif & 62 & 3,23 &, 973
\end{tabular}




\begin{tabular}{lllrr} 
& 10. Sinıf & 53 & 3,43 &, 960 \\
& 11. Sinıf & 55 & 3,34 &, 970 \\
12. Sinıf & 49 & 3,61 & 1,000 \\
Sporla Yaşama Boyutu & 9. Sinıf & 62 & 3,22 &, 975 \\
& 10. Sinıf & 53 & 3,40 & 1,058 \\
11. Sinıf & 55 & 3,28 & 1,032 \\
Aktif Spor Yapma Boyutu & 12. Sinıf & 49 & 3,42 &, 995 \\
& 9. Sinıf & 62 & 3,13 & 1,080 \\
& 10. Sinıf & 53 & 3,24 & 1,205 \\
& 11. Sinıf & 55 & 2,93 & 1,091 \\
& 12. Sinıf & 49 & 3,21 & 1,006 \\
\hline
\end{tabular}

Tablo 6 incelendiğinde genel olarak en yüksek ortalamanın 12. sınıf öğrencilerinde $(\overline{\mathrm{X}}=3,46)$, en düşük ortalamanın 9. sınıf öğrencilerinde $(\bar{X}=3,20)$ olduğu görülmektedir. Alt boyutlara bakıldığında; en yüksek ortalamanın spora ilgi duyma $(\overline{\mathrm{X}}=3,61)$ ve sporla yaşama $(\overline{\mathrm{X}}=3,42)$ boyutlarında 12. sinıf öğrencilerinde, aktif spor yapma boyutunda $(\bar{X}=3,24)$ ise 10 . sinıf öğrencilerinde; en düşük ortalamaların ise spora ilgi duyma $(\bar{X}=3,23)$ ve sporla yaşama $(\bar{X}=3,22)$ boyutlarında 9. sınıf öğrencilerinde, aktif spor yapma boyutunda $(\bar{X}=2,93)$ ise 11 . sınıf öğrencilerinde olduğu görülmektedir.

Öğrencilerin sınıf seviyelerine göre spora ilişkin tutum ortalamaları arasındaki farkın anlamlı olup olmadığının belirlenmesinde ANOVA kullanılmış ve elde edilen sonuçlar Tablo 7'de sunulmuştur.

Tablo 7

Öğrencilerin Sınıf Seviyelerine Göre Spora Yönelik Tutumlarına İlişkin ANOVA Sonuçları

\begin{tabular}{llrrrrr} 
& Varyansın & & & & & \\
& Kaynağ 1 & KT & sd & KO & F & p \\
& Gruplar arasi & 2,442 & 3 &, 814 &, 879 &, 453 \\
GENEL & Gruplar içi & 199,000 & 215 &, 926 & & \\
& Toplam & 201,442 & 218 & & & \\
& Gruplar arasi & 4,231 & 3 & 1,410 & 1,481 &, 221 \\
& Gruplar içi & 204,798 & 215 &, 953 & & \\
Spora İlgi Duyma Boyutu & Toplam & 209,029 & 218 & & & \\
& Gruplar arası & 1,485 & 3 &, 495 &, 480 &, 696 \\
& Gruplar içi & 221,553 & 215 & 1,030 & & \\
Aktif Spor Yapma Boyutu & Toplam & 223,038 & 218 & & & \\
& Gruplar arası & 3,192 & 3 & 1,064 &, 881 &, 452 \\
& Gruplar içi & 259,769 & 215 & 1,208 & & \\
\hline
\end{tabular}

Spora yönelik tutumlara ilişkin ANOVA sonucunda ölçek genelinde ve tüm alt boyutlarda gruplar arası ortalamaların istatistiksel olarak anlamlı derecede farklılaşmadığı $(\mathrm{F}=, 879,1,481,, 480$, ,881 p>.05) görülmektedir.

Tablo 8

Sportif Etkinliklere Katılım Durumlarına İlişkin T-Testi Sonuçları

\begin{tabular}{|c|c|c|c|c|c|c|c|}
\hline & $\begin{array}{l}\text { Sportif Etkinliklere Katılım } \\
\text { Durumlar1 }\end{array}$ & $\mathrm{N}$ & $\bar{X}$ & SS & $\mathrm{t}$ & $\mathrm{p}$ & $\begin{array}{r}\text { Etki } \\
\text { Büyüklüğü }\end{array}$ \\
\hline \multirow{2}{*}{ GENEL } & Katılırım & 121 & 3,58 & 993 & \multirow{2}{*}{4,849} & \multirow{2}{*}{,000 } & \multirow{2}{*}{0.6} \\
\hline & Katılmam & 98 & 2,97 & 807 & & & \\
\hline \multirow{2}{*}{ Spora İlgi Duyma Boyutu } & Katılırım & 121 & 3,62 & 1,042 & \multirow{2}{*}{4,038} & \multirow{2}{*}{,000 } & \multirow{2}{*}{0.5} \\
\hline & Katılmam & 98 & 3,10 & 812 & & & \\
\hline \multirow{2}{*}{ Sporla Yaşama Boyutu } & Katılırım & 121 & 3,61 & 1,037 & \multirow{2}{*}{4,909} & \multirow{2}{*}{,000 } & \multirow{2}{*}{0.6} \\
\hline & Katılmam & 98 & 2,97 & 858 & & & \\
\hline \multirow{2}{*}{ Aktif Spor Yapma Boyutu } & Katılırım & 121 & 3,45 & 1,074 & \multirow{2}{*}{5,134} & \multirow{2}{*}{, 000} & \multirow{2}{*}{0.7} \\
\hline & Katılmam & 98 & 2,72 & ,994 & & & \\
\hline
\end{tabular}


Tablo 8 incelendiğinde sportif etkinliklere katılırım diyen öğrencilerin ortalamalarının $(\overline{\mathrm{X}}=3,58)$ sportif etkinliklere katılmam diyen öğrencilerin ortalamalarından $(\overline{\mathrm{X}}=2,97)$ yüksek olduğu görülmektedir. Alt boyutlara bakıldığında; tüm alt boyutlarda da sportif etkinliklere katılırım diyen öğrencilerin ortalamalarının sportif etkinliklere katılmam diyen öğrencilerin ortalamalarından yüksek olduğu görülmektedir. $\mathrm{T}$ testi sonucuna göre gruplar arası ortalama farkların anlamlı olduğu görülmektedir ( $\mathrm{p}<.05)$.

Ölçek genelinde görülen bu anlamlı farklılığın etki büyüklüğ̈ orta düzeydedir (Cohen's $\mathrm{d}=0.6$ ). Spora ilgi duyma (Cohen's $\mathrm{d}=0.5$ ) ve sporla yaşama (Cohen's $d=0.6$ ) boyutlarındaki etki büyüklükleri orta düzeyde, aktif spor yapma boyutunda görülen etki büyüklügüu ise geniş (Cohen's $\mathrm{d}=0.7$ ) düzeydedir.

\section{Sonuç, Tartıșma ve Öneriler}

Alanyazın incelendiğinde ortaöğretim öğrencilerinin spora yönelik tutumları üzerinde sınırlı sayıda çalışma olduğu, genellikle üniversite öğrencilerinin spora yönelik tutumları üzerinde çalışmaların yapıldığı (Belli, Bedir ve Turhan, 2019; Efek, Sivrikaya ve Sadık, 2018; Göksel, Caz, Yazıcı ve İkizler, 2017; Kalfa, 2019; Mirsafian, 2014; Önal, Yılmaz, Kaldırımcı ve Ağduman, 2017; Türkmen ve Abdurahimoğlu, 2016; Varol, 2017; Varol, Varol ve Türkmen, 2017; Yavuz ve Yücel, 2019; Yıldı, Arı ve Y1lmaz, 2017) görülmektedir. Bununla birlikte öğrencilerin beden eğitimi ve spor dersine ilişkin tutumları üzerinde yapılan çalışmalar da (Akandere, Özyalvaç ve Duman, 2010; Göksel ve Caz, 2016; Keskin, Öncü ve Küçük Kılıç, 2016; Özyalvaç, 2010; Sivrikaya ve Kılçık, 2017; Yaldız ve Özbek, 2018) görülmektedir.

Öğrencilerinin spora ilişkin tutumları genel olarak orta düzeydedir. Alt boyutlarda; spora ilgi duyma boyutunda yüksek, sporla yaşama ve aktif spor yapma alt boyutlarında orta düzeydedir. Araştırma sonuçları ile benzer şekilde Yanık ve Çamlıyar (2015) ve Yıldırım, Araç Ilgar ve Uslu (2018) da öğrencilerin beden eğitimi ve spora ilişkin orta düzeyde tutuma sahip oldukları sonucuna ulaşmışlardır. Literatür incelemelerinde Kargın Göktaş ve Şentürk (2019) çalışmalarında öğrencilerin tutumlarının genel olarak yüksek düzeyde olduğu, alt boyutlarda da öğrencilerin tutumlarının spora ilgi duyma, sporla yaşama ve aktif spor yapma alt boyutlarında da yüksek düzeyde olduğu sonucuna ulaşmışlardır. Bununla birlikte öğrencilerin beden eğitimi ve spora ilişkin yüksek düzeyde tutuma sahip oldukları yönünde benzer çalışmaların varlığı da görülmektedir (Güllü, Güçlü ve Arslan, 2009; Özkurt ve Pepe, 2016).

Öğrencilerin spora ilişkin tutumları cinsiyet değişkenine göre anlamlı olarak farklılaşmamaktadır. Araştırma sonuçları ile benzer şekilde Göksel ve Caz (2016) çalışmalarında spora ilişkin tutum üzerinde cinsiyetin anlamlı farklılık göstermediği sonucuna ulaşmışlardır. Bununla birlikte ortaöğretim öğrencilerinin spora yönelik tutumlarının incelendiği çalışmalarında erkek öğrencilerin spora ilişkin tutumlarının yüksek olduğu sonucuna ulaşan çalışmalar da görülmektedir (Araç Ilgar ve Uslu, 2018; Çelik ve Pulur, 2011; Güllü, Güçlü ve Arslan, 2009; Kangalgil, Hünük ve Demirhan, 2006; Kargın Göktaş ve Şentürk, 2019; Özkurt ve Pepe, 2016; Şişko ve Demirhan, 2002).

Sınıf seviyeleri öğrencilerin spora ilişkin tutumları üzerinde etken bir değişken değildir. Araştırma sonuçlarını destekler nitelikte Kangalgil, Hünük ve Demirhan (2006) ve Güllü, Güçlü ve Arslan (2009) ortaöğretim öğrencilerinin spora ilişkin tutumları üzerinde sınıf seviyesini etken bir değişken olmadığı sonucuna ulaşmışlardır. Araç Ilgar ve Uslu (2018) ise çalışmalarında sınıf düzeyi yükseldikçe öğrencilerin spora yönelik tutum düzeylerinin düştüğü sonucuna ulaşmışlardır.

Öğrencilerin spora yönelik tutumları sportif etkinliklere katılım durumlarına göre anlamlı olarak farklılaşmaktadır. Ölçek genelinde sportif etkinliklere katılırım diyen öğrencilerin ortalamaları sportif etkinliklere katılmam diyen öğrencilerin ortalamalarından yüksektir. Alt boyutlarda da sportif etkinliklere katılırım diyen öğrencilerin ortalamaları sportif etkinliklere katılmam diyen öğrencilerin ortalamalarından yüksektir. Ölçek genelinde görülen bu anlamlı farklılığın etki büyüklüğü orta düzeydedir. Spora ilgi duyma ve sporla yaşama boyutlarındaki etki büyüklükleri orta düzeyde, aktif 
spor yapma boyutunda görülen etki büyüklüğü ise geniş düzeydedir. Araştırma sonuçlarını destekler nitelikte sportif ekinliklere katılan öğrencilerin spora ilişkin tutumlarının yüksek olduğu sonucuna ulaşan çalışmalar görülmektedir (Çelik ve Pulur, 2011; Güllü, Güçlü ve Arslan, 2009; Kangalgil, Hünük ve Demirhan, 2006; Yanık ve Çamlıyar, 2015).

Araştırmacılar farklı örneklem gruplar üzerinde çalışmalar yaparak ortaöğretim öğrencilerinin spora yönelik tutumlarını inceleyebilirler. Araştırma sonuçları ortaöğretim öğrencilerinin spora yönelik orta düzey tutum geliştirdikleri yönündedir. Dijitalleşmenin çok hızlı ilerlediği bu günlerde çalışmadan böyle bir sonuç çıkması çok da şaşırtıcı bir durum değildir. Bu kapsamda ilgili okul müdürlükleri ve beden eğitimi ve spor öğretmenleri ortaöğretim öğrencilerinin spora ilişkin tutumlarını olumlu yönde etkileyecek planlamalar yapabilirler. Bölgedeki ünlü sporcular okullara getirilerek veya il düzeyinde sporu sevdirecek ve spora yöneltecek programlar hazırlanabilir. Bunlara benzer programlar planlanarak öğrencilerin spora yönelmeleri ve bu anlamda telefon, tablet vb araçlara yönelmelerinin bir anlamda önüne geçilebilir.

Açıklamalar: $\mathrm{Bu}$ çalışma 18 Nisan 2020 tarihinde 11. Uluslararası Eğitimde Yeni Yönelimler Kongresinde (ICONTE) özet bildiri olarak sunulmuştur.

\section{Kaynaklar}

Akandere, M., Özyalvaç, N. T. ve Duman, S. (2010). Ortaöğretim öğrencilerinin beden eğitimi dersine yönelik tutumları ile akademik başarı motivasyonlarının incelenmesi (Konya Anadolu Lisesi örneği). Selçuk Üniversitesi Sosyal Bilimler Enstitüsü Dergisi, (24), 1-10.

Akın, G. (2017). Yaşlanmada fiziksel aktivite ve egzersizin yeri. Ahi Evran Üniversitesi Sosyal Bilimler Enstitüsü Dergisi, 3(2), 271-280.

Armstrong, N., Welsman, J. R. and Kirby, B. J. (1998). Peak oxygen uptake and maturation in 12-yr olds. Medicine \& Science in Sports \& Exercise, 30(1), 165-169.

Belli, E., Bedir, F. ve Turhan, M. (2019). Üniversite öğrencilerinin spora yönelik tutumları ile yaşam doyumları arasındaki ilişkinin incelenmesi. Erzurum Teknik Üniversitesi Sosyal Bilimler Enstitüsü Dergisi, (9), 89-103.

Büyüköztürk, Ş. (2014). Sosyal bilimler için veri analizi el kitabı. Ankara: Pegem Akademi.

Çelik, Z. ve Pulur, A. (2011). Ortaöğretim öğrencilerinin beden eğitimi ve spora ilişkin tutumları. Yüzüncü Yıl Üniversitesi Ĕ̈itim Fakültesi Dergisi, 8(Özel).

Çınar, V. (2015). Spor ve beslenme. İçinde Demir, E. (Ed.), Spor bilimlerine girişs (ss. 109-149). Ankara: Nobel.

Efek, E., Sivrikaya, Ö. ve Sadık, R. (2018). Spor bilimleri alanında okuyan üniversite öğrencilerinin ahlaki gelişim düzeyleriyle spor tutumları arasındaki ilişkinin incelenmesi. Journal of Social And Humanities Sciences Research (JSHSR), 5(29), 3895-3903.

George, D. and Mallery, M. (2010). SPSS for windows step by step: A simple guide and reference. 17,0 update (10a ed.). Boston: Pearson.

Göksel, A. G. ve Caz, Ç. (2016). Anadolu Lisesi öğrencilerinin beden eğitimi dersine yönelik tutumlarının incelenmesi. Marmara Üniversitesi Spor Bilimleri Dergisi, 1(1), 1-9.

Göksel, A. G., Caz, Ç., Yazıcı, Ö. F. ve İkizler, H. C. (2017). Farklı bölümlerdeki öğrencilerin spora yönelik tutumlarının karşılaştırılması: Marmara Üniversitesi örneği. Spor ve Performans Araştırmaları Dergisi, 8(2), 123-134. 
Göktaş, N. ve Şentürk, H. (2019). Spor lisesi öğrencilerinin okul iklimi algıları ile spora yönelik tutumları arasındaki ilişki. SPORMETRE Beden Eğitimi ve Spor Bilimleri Dergisi, 17(3) , 7892.

Güllü, M., Güçlü, M. ve Arslan, C. (2009). Ortaöğretim öğrencilerinin beden eğitimi dersine ilişkin tutumlarının incelenmesi. Sport Sciences, 4(4), 273-288.

Hogg, M. A. and Vaughan, G. M. (2006). Social Psychology. (Çev. İ. Yıldız ve A. Gelmez). Ankara: Ütopya Yayınevi.

İnceoğlu, M. (2011). Tutum algı iletişim. Ankara: Siyasal Kitabevi.

Jianzhong, X. (2004). Impacts of sports and health course standards on the psychological health of students. PE Teachers, (3), 61-63.

Kalfa, M. (2019). Diş hekimliği fakültesindeki öğrencilerinin spora yönelik tutumları. SPORMETRE Beden Eğitimi ve Spor Bilimleri Dergisi, 17(1), 165-181.

Kangalgil, M., Hünük, D. ve Demirhan, G. (2006). İlköğretim, lise ve üniversite öğrencilerinin beden eğitimi ve spora ilişkin tutumlarının karşılaştırılması. Spor Bilimleri Dergisi, 17(2), 48-57.

Karahüseyinoğlu, M. F. (2015). Spor sosyolojisi. İçinde Demir, E. (Ed.), Spor bilimlerine giriş (ss. 209-252). Ankara: Nobel.

Keskin, N., Öncü, E. ve Küçük Kılıç. S. (2016). Ortaokul öğrencilerinin beden eğitimi dersine yönelik tutum ve öz-yeterlikleri. SPORMETRE Beden Eğitimi ve Spor Bilimleri Dergisi, 14(1), 93107.

Mengütay, S., Demir, A. ve Coşan, F. (2002). Olimpiyatlar için sporcu kaynă̆ı projesi, Türkiye'de çocukların spora yönlendirilmesinde uygulama modeli, temel spor eğitimi. (1.Bask1) İstanbul: Olimpiyat Oyunları Hazırlık ve Düzenleme Kurulu, Eğitim Yayınları .

Millî Eğitim Bakanlı̆̆ı. (2018). Ortaöğretim Beden Eğitimi ve Spor Dersi Programı. http://mufredat.meb.gov.tr/ProgramDetay.aspx?PID=334 adresinden 25.04.2020 tarihinde erişilmiştir.

Mirsafian, H. (2014). Attitudes of Iranian male university students toward sport and exercise with reference to age, educational level, and field of study. Physical Culture \& Sport. Studies \& Research, 64(1), 18-28.

Önal, L., Yılmaz, H. H., Kaldırımcı, M. ve A ̆gduman, F. (2017). Atatürk üniversitesi öğrencilerinin spora karşı tutumları ile yaşam kaliteleri arasındaki ilişkinin incelenmesi. Muş Alparslan Üniversitesi Uluslararası Spor Bilimleri Dergisi, 1(1), 26-34.

Özyalvaç, N. T. (2010). Ortaöğretim öğrencilerinin beden eğitimi dersine yönelik tutumları ile akademik başarı motivasyonlarının incelenmesi. Doktora tezi. Selçuk Üniversitesi, Sağlık Bilimleri Enstitüsü, Konya.

Pepe, K. ve Özkurt, R. (2016). Kadın ve erkek lise öğrencilerinin beden eğitimi ve spor dersine yönelik tutumlarının araştırılması. Uluslararası Spor Egzersiz ve Antrenman Bilimi Dergisi, 2(3), 93-101. 
Pepe, K., Kara, A., Özkurt, R. ve Dalaman, O. (2019). Aktif spor yapan amatör sporcuların spor ortamında fair play (sportmen) davranışlarının incelenmesi. Ahi Evran Üniversitesi Sosyal Bilimler Enstitüsü Dergisi, 5(2), 497-506.

Sivrikaya, Ö. ve Kılçık, M. (2017). İlköğretim okulları 2. kademe öğrencilerinin beden eğitimi ve spor dersine ilişkin tutumlarının belirlenmesi (Düzce örneği). CBÜ Beden Eğitimi ve Spor Bilimleri Dergisi, 12(1), 1-15.

Şentürk, H. E. (2015). Sportif tutum ölçeği: Geliştirilmesi, geçerliliği ve güvenirliği. CBÜ Beden Ĕ̈itimi ve Spor Bilimleri Dergisi, 7(2), 8-18.

Şişko, M., ve Demirhan, G. (2002). İlköğretim okulları ve liselerde öğrenim gören kız ve erkek öğrencilerin beden eğitimi ve spor dersine ilișkin tutumları. Hacettepe Üniversitesi Ĕğitim Fakültesi Dergisi, 23(23).

Tabachnick, B., G. ve Fidell, L., S. (2015). Using multivariate statistics. (Çev. M. Baloğlu). Ankara: Nobel.

Taşdemir, M. (2003). Eğitimde planlama ve değerlendirme. Ankara: Ocak Yayınevi.

Tekindal, S. (2009). Okullarda ölçme ve değerlendirme yöntemleri. Ankara: Nobel

Turgut, M. F. (1995). Eğitimde ölçme ve değerlendirme metotları. Ankara: Yargıcı Matbaası.

Türkmen, M., Abdurahimoğlu, Y., Varol, S. ve Gökdağ, M. (2016). İslami ilimler fakültesi öğrencilerinin spora yönelik tutumlarının incelenmesi (Bartin Üniversitesi örneği). Uluslararası Güncel Ĕgitim Araştırmaları Dergisi, 2(1), 48-59.

Varol, R. (2017). Üniversite ögrencilerinin spora yönelik tutumları ve kadınların spor etkinliklerine katılımlarına dair görüşlerinin incelenmesi (Bartın Üniversitesi örneği). Yüksek Lisans Tezi. Bartın Üniversitesi, Bartın.

Varol, R., Varol, S. ve Türkmen, M. (2017). Bartın üniversitesinde öğrenim gören öğrencilerin spora yönelik tutumlarının belirlenmesi. Uluslararası Kültürel ve Sosyal Araştırmalar Dergisi (UKSAD), 3(2), 316-329.

Yaldız, A. S. ve Özbek, O. (2018). İlköğretim Okullarında beden eğitimi dersine yönelik öğrenci ve ana-baba tutumları. Kastamonu Ĕgitim Dergisi, 26(1), 75.

Yanık, M. ve Çamlıyer, H. (2015). Ortaöğretim 9. sınıf öğrencilerinin beden eğitimi ve spora ilişkin tutumları ile okula yabancılaşma düzeyleri arasındaki ilişkinin belirlenmesi. Uluslararası Spor Egzersiz ve Antrenman Bilimi Dergisi, 1(1), 9-19.

Yavuz, C. ve Yücel, A. S. (2019). Spor yöneticiliği bölümü öğrencilerinin spora yönelik tutumlarının bazı değişkenlere göre incelenmesi. Elektronik Sosyal Bilimler Dergisi, 18(72), 2050-2058.

Yetim, A. (2000). Social aspects of sport. Gazi Journal of Physical Education and Sport Sciences, $5(1), 63-72$.

Yıldırım, M., Araç Ilgar, E. ve Uslu, S. (2018). Lise öğrencilerinin spora yönelik tutumlarının incelenmesi. Electronic Turkish Studies, 13(27), 1712-1727.

Yıldız, A. B., Arı, Ç. ve Yılmaz, B. (2017). Üniversite öğrencilerinin spora yönelik tutumlarının incelenmesi (Ankara Yıldırım Beyazıt Üniversitesi örneği). Muş Alparslan Üniversitesi Uluslararası Spor Bilimleri Dergisi, 1(1), 35-45. 


\section{Extended Abstract}

\section{Introduction}

The fact that secondary school students of developmental age are healthy individuals is closely related to how much they include sports activities in their lives. In this regard, secondary school students' attitudes toward sports were considered important, and with this study, it was aimed to describe secondary school students' attitudes toward sports.

\section{Method}

\section{Research Model}

The screening model was used in this study. In the first section of the study, it was aimed to describe secondary school students' attitudes toward sports. In the second section of the study, it was investigated whether the variables of gender, grade level, and participation in sports activities showed significant differences in students' attitudes toward sports.

\section{Study Group}

The accessible population of the study consisted of Anatolian high school students studying in the center of Kirşehir. Two hundred thirty-four students selected randomly from this population constituted the sample of the study. Fifteen of the measurement instruments sent to students were not evaluated due to reasons such as incorrect coding and blanking, and the data obtained from a total of 219 students were evaluated. A voluntary basis was required in filling out the measurement instruments.

\section{Instruments}

In the study, the personal information form (PIF) prepared by the researcher and the "SportOriented Attitude Scale" developed by Şentürk (2015) to determine students' attitudes toward sports were used in the data collection process. The Sport-Oriented Attitude Scale consisted of 25 items and 3 dimensions. Cronbach's alpha for the overall scale was found to be .97. It is a 5-point Likert scale.

\section{Data Analysis}

The data obtained were uploaded to the SPSS 20.0 package program for analysis. A significance level of 0.05 was used to test the research data. Frequency (f), percentage (\%), weighted average $(\overline{\mathrm{X}})$, and standard deviation $(\mathrm{SD})$ values were used in the analysis of the descriptive data obtained. Before relational statistics methods, the homogeneity of the data was examined, and whether the data showed normal distribution was examined. The skewness (-.357) and kurtosis (-.261) values of the Sport-Oriented Attitude Scale indicated that the data were normally distributed (Büyüköztürk, 2014; George and Mallery, 2010). In accordance with these results, parametric hypothesis tests were used in the analysis of the research data. Cohen's $d$ was used to calculate the effect size of the significant difference in the independent t-test results.

\section{Findings}

Students' attitudes toward sports were generally $(\bar{X}=3.36)$ moderate. It was observed that the average of male students $(\overline{\mathrm{X}}=3.36)$ was higher than the average of female students $(\overline{\mathrm{X}}=3.27)$.

As a result of the independent samples t-test performed to determine whether students' attitudes toward sports differed significantly according to their gender, it was observed that the average differences between the groups were not statistically significant $(p>.05)$ in the overall scale and in the sub-dimensions. 
As a result of the one-factor ANOVA performed to determine whether students' attitudes toward sports differed significantly according to their grade levels, it was observed that the averages between the groups did not differ statistically significantly $(\mathrm{F}=.879,1.481, .480, .452 \mathrm{p}>.05)$ in the overall scale and in all sub-dimensions.

As a result of the independent samples t-test performed to determine whether students' attitudes toward sports differed significantly according to participation in sports activities, it was observed that the average differences between the groups were statistically significant in the overall scale and in all sub-dimensions ( $\mathrm{p}<.05)$. The effect size of this significant difference observed in the overall scale was moderate (Cohen's $\mathrm{d}=0.6$ ).

\section{Results, Conclusion and Suggestion}

Students' attitudes toward sports were generally moderate. Similarly to the results of the study, Yanık and Çamlıyar (2015) and Yıldırım, Araç Ilgar and Uslu (2018) also concluded that students had a moderate attitude toward physical education and sports. In the literature review, Kargın Göktaş and Şentürk (2019) concluded in their study that students' attitudes were generally high. Nevertheless, there are also similar studies indicating that students have a high level of attitude toward physical education and sports (Güllü, Güçlü and Arslan, 2009; Özkurt and Pepe, 2016).

Students' attitudes toward sports did not differ significantly according to the variable of gender. Similarly to the results of the study, Göksel and Caz (2016) concluded in their study that gender had no significant difference in attitudes toward sports. Nevertheless, in the studies in which secondary school students' attitudes toward sports were examined, there are also studies indicating that male students' attitudes toward sports are high (Araç Ilgar and Uslu, 2018; Çelik and Pulur, 2011; Güllü, Güçlü and Arslan, 2009; Kangalgil, Hünük and Demirhan, 2006; Kargın Göktaş and Şentürk, 2019; Özkurt and Pepe, 2016; Şişko and Demirhan, 2002).

Grade level was not an effective variable on students' attitudes toward sports. Kangalgil, Hünük and Demirhan (2006) and Güllü, Güçlü and Arslan (2009) concluded that grade level was not an effective variable on secondary school students' attitudes toward sports, supporting the results of this study. In the study of Araç Ilgar and Uslu (2018), it was determined that students' levels of attitudes toward sports decreased as the grade level increased.

Students' attitudes toward sports differed significantly according to their participation in sports activities. The average of students who indicated that they would participate in sports activities was higher. The effect size of the significant difference was moderate. There are studies concluding that students who participate in sports activities have high levels of attitudes toward sports, supporting the results of this study (Çelik and Pulur, 2011; Güllü, Güçlü and Arslan, 2009; Kangalgil, Hünük and Demirhan, 2006; Yanık and Çamlıyar, 2015).

Researchers can investigate secondary school students' attitudes toward sports by conducting studies on different sample groups. In this context, the relevant school directorates and physical education and sports teachers can make plans that will positively affect secondary school students' attitudes toward sports. Famous athletes in the region can be invited to schools or programs that will popularize sports and direct students to sports can be prepared at the provincial level. 